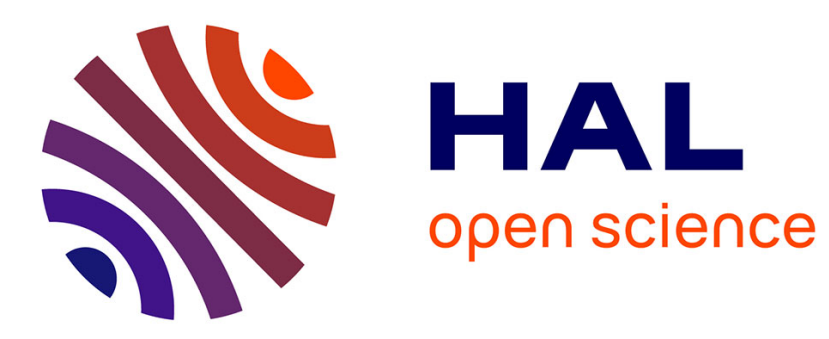

\title{
Predation in Off-Patent Drug Markets
}

Laurent Granier, Sébastien Trinquard

\section{To cite this version:}

Laurent Granier, Sébastien Trinquard. Predation in Off-Patent Drug Markets. Applied Economics, 2012, 44 (17), pp. 2171-2186. 10.1080/00036846.2011.562169 . halshs-00537018

\section{HAL Id: halshs-00537018 https://shs.hal.science/halshs-00537018}

Submitted on 17 Nov 2010

HAL is a multi-disciplinary open access archive for the deposit and dissemination of scientific research documents, whether they are published or not. The documents may come from teaching and research institutions in France or abroad, or from public or private research centers.
L'archive ouverte pluridisciplinaire HAL, est destinée au dépôt et à la diffusion de documents scientifiques de niveau recherche, publiés ou non, émanant des établissements d'enseignement et de recherche français ou étrangers, des laboratoires publics ou privés. 


\section{Predation in Off-Patent Drug Markets}

Laurent Granier, Sébastien Trinquard

Novembre 2010 


\section{GATE Groupe d'Analyse et de Théorie Économique Lyon-St Étienne}

93, chemin des Mouilles 69130 Ecully - France

Tel. +33(0)4 72866060

Fax $+33(0) 472866090$

6, rue Basse des Rives 42023 Saint-Etienne cedex 02 - France

Tel. +33 (0)4 77421960

Fax. $+33(0) 477421950$

Messagerie électronique / Email : gate@gate.cnrs.fr

Téléchargement / Download : http://www.gate.cnrs.fr - Publications / Working Papers 


\title{
Predation in Off-Patent Drug Markets
}

\author{
Laurent Granier ${ }^{\dagger}$ and Sébastien Trinquard
}

October 20, 2010

\begin{abstract}
In 2009, Sanofi-Aventis, whose generic subsidiary is Winthrop, merges with the generic firm, Zentiva. This paper fills the gap in the theoretical literature concerning mergers in pharmaceutical markets. To prevent generic firms from increasing their market share, some brand-name firms produce generics themselves, called pseudogenerics. We develop a Cournot duopoly model by considering the pseudo-generics production as a mergers' catalyst. We show that a brand-name company always has an incentive to purchase its competitor. The key insight of this paper is that the brand-name laboratory can increase its merger gain by producing pseudo-generics beforehand. In some cases, pseudo-generics would not otherwise be produced and this production is then a predatory strategy.

JEL classification: I11, L12.

Keywords: Mergers, Pharmaceutical Market, Predation, Pseudo-Generics.

Mots clefs : Fusions, Marché Pharmaceutique, Prédation, Pseudo-Génériques.

\footnotetext{
† Université de Lyon, Université Lyon 2, F - 69007, Lyon, France. CNRS, GATE Lyon-St Etienne, UMR $\mathrm{n}^{\circ}$ 5824, 69130 Ecully, France. Phone number: +33 (0)4 728660 24; E-mail: granier@ gate.cnrs.fr

*UNOCAM, Paris, France, Phone number: +33 (0)1 428495 03; E-mail: sebastien.trinquard@unocam.fr
} 


\section{Introduction}

In the pharmaceutical market, drug producers apply for patents in order to protect their intellectual property rights. At the patents expiration date, these rights become public property. The production of generic goods, manufactured with the same molecules as the brand-name drugs, can then start to compete with the original product. Generic drugs are certified to be "therapeutically equivalent" to the originator's product. But, for consumers, they may still vary in characteristics such as shape, color, flavor, scoring, packaging, labelling, shelf life and brand loyalty. ${ }^{1}$ Therefore, these goods are not considered as perfect substitutes. The generics market development is an answer from insurers ${ }^{2}$ to the increase in drug spending. A lot of papers study this development. In particular, Caves and alii (1991), Grabowski and Vernon (1992), Frank and Salkever (1992, 1997), Morton $(1999,2000)$ analyze the effect of generics entry on prices and market shares of brand-name products in the United States. However, they do not consider pseudo-generics. ${ }^{3}$ The pseudo-generic is identical to the brand-name product, but is marketed as a generic. In Australia and Canada, pseudo-generics have about one quarter of the generic market. They are also in a strong position in New Zealand, Germany, the UK and Sweden (Hollis, 2002). The significant pseudo-generics production explains our interest in this topic. Indeed, this paper analyzes the pseudo-

\footnotetext{
${ }^{1}$ Due to the trademark protection, the generic manufacturers may not be allowed to produce generic versions that have exactly the same apparence as the brand-name originals (Ching, 2000).

${ }^{2}$ The development of the generics market is favored by the implementation of a right of substitution, of an international nonproprietary name, of formularies, of controls on prescribing doctors and pharmacists, and of controls on drug prices, notably.

${ }^{3}$ In the US, pseudo-generics are also called "authorized generics" (Hollis, 2005).
} 
generics production effects on merger strategies. Thus, the paper fill the gap in the theoretical literature on mergers between brand-name and generic laboratories. In particular, we consider pseudo-generics production as a mergers' catalyst. Some simple stylized facts suggest that the topic addressed in this paper is potentially highly relevant for the pharmaceutical industry. Indeed, we observe mergers between brand companies producing pseudo-generics and generic firms: in 2002, Novartis whose generic subsidiary is Sandoz, acquires Lek, then Sabex and Duranscan in 2004; in 2009, SanofiAventis, whose subsidiary is Winthrop merges with Zentiva. Merger incentives are empirically validated (Scott Morton, 2002).

The economists' interest in pseudo-generics effect on the pharmaceutical market is recent, both at an empirical and theoretical level. At the empirical level, Hollis (2002) is the first paper to consider the effect of pseudo-generics on prices and generics entry. He shows the presence of a first mover advantage. This advantage deters entry and leads to the increase in prices, both for pseudo-generics and brand-name products. Hollis (2002, 2005) concludes that the welfare decreases on the Canadian market. At the theoretical level, Ferrandiz (1999) analyzes the decision to produce pseudo-generics in a market where branded goods are perfect substitutes and where there exists a degree of product differentiation between brand-name drugs and generics. He shows in a model, via simulation outcomes, that it is better for a brand-name firm to produce pseudogenerics than to accept the entry of the generic firm. The brand-name firm takes this decision in order to increase the brand-name price ${ }^{4}$ and its global profit, owing to a market segmentation effect. On the other hand, Kong and Seldon (2004) use a two-stage game model with product differentiation. They find that, if the cross-price effect

\footnotetext{
${ }^{4}$ Frank and Salkever (1992) is the first paper modelizing the price increase of the branded good when the
} 
between the brand-name product and its generic equivalent is sufficiently large, the brand-name incumbent produces the pseudo-generic drug, increasing its profit and deterring generic entry. ${ }^{5}$ From a policy perspective, the results of this research imply that: either the pseudo-generic should be banned, or a period without pseudo-generic should be guaranteed to the first generic firm ${ }^{6}$ (Hollis, 2003). This perspective would justify our merger study. So, we note the presence of generic firms in pharmaceutical markets. Moreover, the merger cases already cited in this introduction show entry deterrence study can be completed by a merger study. The following framework, allowing to analyze merger incentives, explain a concrete fact.

To our knowledge, few theoretical papers analyze mergers between brand-name and generic laboratories. This paper is an attempt to fill that gap. In particular, we consider pseudo-generics production as a merger catalyst. In other words, we study how merger stategies can influence pseudo-generics production. We modelize an industry in which a brand-name firm and a generic firm ${ }^{7}$ compete à la Cournot. Brand-name and generic goods are considered as imperfect substitutes. This model presents a two-stage non-cooperative game. At each stage, the brand-name firm can purchase its generic competitor. But, in the first stage, the brand-name firm can decide to produce pseudogenerics instead. In this framework, the generic laboratory is a Stackelberg leader on the generic market where two homogeneous goods are available: generic and pseudogeneric products. The pseudo-generics production at the initial stage reduces the cost of

\footnotetext{
generic drug enters in the pharmaceutical market.

${ }^{5}$ For comments about Kong and Seldon's (2004) propositions, see Rodrigues (2006) and Kong and Seldon (2006).

${ }^{6}$ In the United States, the 1984 Hatch-Waxman Act, guaranteed a period of six months of exclusivity from the date it starts marketing its generic drug. This patent is set up to favour the generic entry (OECD, 2001).

${ }^{7}$ Indeed, we assume an only one generic firm. Most of the time, trere are a lot of generic firms in a therapeutical class. But qualitatively, our results are robust if several generic manufacturers are initially present and if there is a pattern of future entries.
} 
the merger at the second stage. Indeed, the competition increases and lowers the purchase price of the generic firm. We find three results. First, without pseudo-generics, the brand-name producer always monopolizes the market. Second, the pseudo-generics production may delay the takeover. Indeed, under some conditions, the "delayed" merger dominates the first period merger. Third, the brand-name company can produce pseudo-generics solely to monopolize the industry, even if it is not profitable at first. Indeed, under some market conditions, the pseudo-generics production reduces the brand-name firm's profit, but this firm nonetheless decides to produce this pseudogeneric in order to lower the purchase price of the generic manufacturer. Two conditions must be satisfied to insure the profitability of this strategy: the loss incurred by the pseudo-generics production over a period must not be too significant. Moreover, the discounted value of the gain associated with the reduction in the purchase price must be high enough. In this situation, pseudo-generics production must be analyzed as a predatory strategy. In the predation literature, most of papers analyze predatory pricing. By this way, Saloner (1987) analyzes mergers in a predation context. Contrary to Saloner (1987), in our paper, the predation is provoked by pseudo-generics production.

In our paper, we extend Kong and Seldon (2004). The latter is the only paper concerning both anti-competitive practices in the pharmaceutical market and pseudogenerics production. Our treatment differs on two points. On one hand, we consider that the generic product enters before the pseudo-generic product, and so, benefits from the generic market leadership ${ }^{8}$ (Grabowsky and Vernon, 1992). On the other hand, the monopolization of the pharmaceutical market can thus take place only by mergers

\footnotetext{
${ }^{8}$ Grabowski and Vernon (1992) examined data on 18 major orally-administrated drug products subject to generic competition between 1983 and 1987 and these data are consistent with the hypothesis of firstmover advantages in generic drug markets.
} 
because the generic product is present in the market before the pseudo-generic product. So, we study mergers and not barriers to entry, contrary to Kong and Seldon (2004).

The rest of the paper is organized into five sections. Section 2 sets up the basic model. Section 3 shows how merger incentives are modified with the pseudo-generic entry. In section 4, we analyze effects of merger strategies on pseudo-generics production. Finally, section 5 concludes.

\section{Basic model}

Firstly, we present the assumptions of the model. Then, we study the benchmark. We start by investigating the conditions under which the duopolistic situation is sustainable, assuming that pseudo-generics can not be produced. In this framework, we complete the study by analyzing the incentives to merge.

\subsection{Assumptions}

We study a two-firm industry in which a brand-name laboratory and a generic firm compete à la Cournot. By assumption, the price-elasticity in the generic market is higher than the price-elasticity in the branded market as in Frank et Salkever (1992). The utility results from the satisfaction obtained from the consumption of the quantity $q_{b}$ of brand-name goods and the quantity $Q_{G}$ of its generic substitute, with $Q_{G}=q_{g}+q_{p g}$. Note that $q_{g}$ is the generic quantity and $q_{p g}$ is the pseudo-generic quantity. We assume that, for consumers, generic and pseudo-generic goods are 
homogeneous (Hollis, 2002). In a compromise between generality and tractability, we assume, as Kong and Seldon (2004), that the quadratic utility function of the representative consumer ${ }^{9}$ is the following one:

$$
\begin{aligned}
U & =V_{0}+U\left(q_{b}, Q_{G}\right) \\
& =V_{0}+\zeta_{b} q_{b}+\zeta_{G} Q_{G}-\frac{1}{2}\left(\alpha q_{b}^{2}+2 \gamma q_{b} Q_{G}+\beta Q_{G}^{2}\right) .
\end{aligned}
$$

where $V_{0}$ reflects the utility derived from a competitive numeraire sector. We assume $\zeta_{b}>0, \zeta_{G}>0, \alpha>0, \beta>0, \gamma>0$, and $\alpha<\beta$ to take into account the preference for brand-name products. To simplify and without loss of generality, we normalize the size of the market to unity, i.e $\zeta_{G}=\zeta_{b}=1$. To ensure the concavity of utility and profit functions, we assume $\alpha \beta>\gamma^{2}$. $\frac{\gamma^{2}}{\alpha \beta}$ expresses the degree of product differentiation, ranging from 0 for independent goods to 1 for perfect substitutes (as $\alpha<\beta$, we often compare $\alpha$ and $\gamma$ to analyze product differentiation). From (1), one can derive linear inverse demand relations:

$$
\begin{gathered}
p_{G}=\frac{\partial U}{\partial Q_{G}}=1-\beta Q_{G}-\gamma q_{b}, \\
p_{b}=\frac{\partial U}{\partial q_{b}}=1-\alpha q_{b}-\gamma Q_{G} .
\end{gathered}
$$

Finally, we assume that there is no production cost. This assumption makes it easier to capture the product differentiation effects on firms' strategies. Furthermore, we

\footnotetext{
${ }^{9}$ The representative consumer is a physician, considered as a perfect agent for his or her patients.
} 
assume no entry threats. ${ }^{10}$ Nevertheless, if we consider entries, entry deterrence holds by introducing fixed costs in the model. In this framework, if potential entrants have fixed costs above a computable threshold, our results hold. Moreover, this threshold is all the more low because, once the merger achieved, pseudo-generics are generally produced. Therefore, entry is even less encouraged (Kong and Seldon, 2004).

\subsection{Duopoly without pseudo-generic products}

We study the conditions under which the duopolistic situation is sustainable, assuming that pseudo-generics can not be produced. We assume that a brand-name laboratory and a generic firm compete à la Cournot. Let $\Pi_{b}^{D}$ be the brand-name firm's profit function and $\Pi_{g}^{D}$ be the generic laboratory's profit function. Note that $Q_{G}=q_{g}$ in this case. We derive the equilibrium outputs from the first order conditions (see appendix A):

$$
\begin{aligned}
& q_{g}^{D^{*}}=\frac{2 \alpha-\gamma}{4 \alpha \beta-\gamma^{2}} . \\
& q_{b}^{D^{*}}=\frac{2 \beta-\gamma}{4 \alpha \beta-\gamma^{2}} .
\end{aligned}
$$

Remark 1 The duopoly exists if product differentiation is high enough $(\gamma<2 \alpha)$.

\footnotetext{
${ }^{10}$ Our model is not a model of entry since we do not focus on entry deterrence. Many endogenous mergers models (see for instance Kamien and Zang, 1990) proceed in the same way. Once a firm entered the market, the settle costs are paid. Moreover, pseudo-generics may be manufactured on the same production lines as their name-brand equivalents. Because of these two reasons, we assume no fixed costs. However, our results are robust from a threshold of fixed costs if we assume such costs.
} 
On the brand-name market, if product differentiation is not too high $(\gamma>2 \alpha)$, the own-price effect on the brand-name product is very low compared to the own-price effect on the generic product and to the cross-price effect. Therefore, brand-name goods are produced in very large quantities. Thus, the price is negative in the generic market and the generic firm has no incentive to produce. We derive the equilibrium profits:

$$
\begin{aligned}
& \Pi_{b}^{D *}=\frac{\alpha(2 \beta-\gamma)^{2}}{\left(4 \alpha \beta-\gamma^{2}\right)^{2}} . \\
& \Pi_{g}^{D *}=\frac{\beta(2 \alpha-\gamma)^{2}}{\left(4 \alpha \beta-\gamma^{2}\right)^{2}} .
\end{aligned}
$$

\subsection{Merger without pseudo-generic products}

Here, we are interested in the possibility that the brand firm acquires the generic firm in order to monopolize the market. ${ }^{11}$ Thus, the following non-cooperative game is played: the brand-name firm chooses between two events. Either merge with the generic firm, or stay in the duopolistic industry. We call status quo this second event (see figure 1 for the extended form of the game).

\footnotetext{
${ }^{11}$ Two reasons rule out the possibility that the generic firm initiate the takeover. First, no generic firm bought back a brand-name firm to this day. Second, it is easier for the brand-name firm to initiate the takeover. Indeed, it benefited from a monopolistic situation thanks to its patent and because of the brandname demand inelasticity.
} 


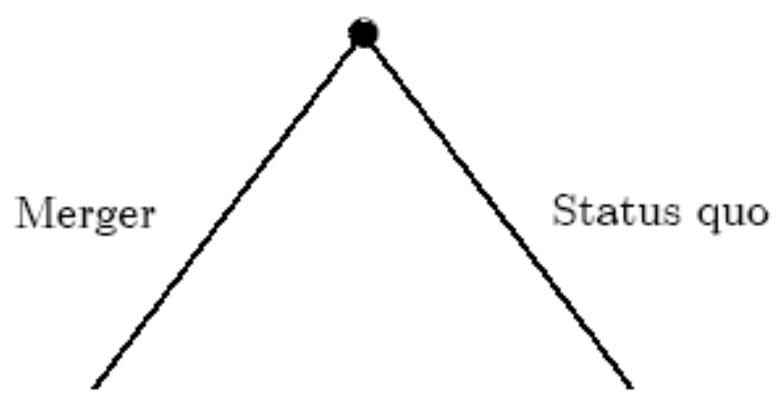

- Duopoly

\section{Figure 1}

In this game, the brand-name firm makes a bid for the generic firm. The generic firm gives a reservation price below which it refuses to be sold. If the bid is superior or equal to the reservation price, the brand-name laboratory purchases the generic firm. Otherwise, the status quo is equilibrium of this game. We look for the Nash equilibrium of this game. Therefore, we determine the incentives to merge. Firstly, we study the monopoly profit. Indeed, the merger incentive depends on the difference between the monopoly profit and the merger costs.

\subsubsection{The monopoly, goal of the merger}

In order to determine the equilibrium of the game, we need the monopoly profit function. Indeed, the merger leads to this market structure. In the previous section, we showed that a de facto monopoly exists if and only if the product differentiation is not too high $(\gamma>2 \alpha)$. For a brand-name market price-sensitivity below this threshold $(\gamma>2 \alpha)$, the generic firm exits the market. The monopoly can also exist because of a merger. This is possible if product differentiation is high enough $(\gamma<2 \alpha)$. 
Let us study the case where the branded firm has a monopoly power and produces generics (pseudo-generics). Let us note its profit $\Pi_{b}^{M}$. We derive the equilibrium outputs from the first order conditions (see appendix B):

$$
\begin{aligned}
q_{b}^{M *} & =\frac{1}{2} \frac{\beta-\gamma}{\alpha \beta-\gamma^{2}} . \\
q_{g}^{M *} & =\frac{1}{2} \frac{\alpha-\gamma}{\alpha \beta-\gamma^{2}} .
\end{aligned}
$$

We derive the equilibrium profits:

$$
\Pi_{b}^{M *}=\frac{1}{4} \frac{\beta-2 \gamma+\alpha}{\alpha \beta-\gamma^{2}}
$$

If product differentiation is not too high $(\alpha<\gamma)$, the monopoly produces exclusively brand-name goods. Let $\Pi_{b}^{M M}$ be its profit function. We derive the equilibrium output from the first order condition (see appendix C):

$$
q_{b}^{M M *}=\frac{1}{2 \alpha} .
$$

We derive the equilibrium profit:

$$
\Pi_{b}^{M M *}=\frac{1}{4 \alpha} .
$$


Remark 2 If product differentiation is high enough $(\gamma<\alpha)$, the monopoly produces brand-name and generic goods. Indeed, inter-market competition is not too intensive.

Intuitively, if product differentiation is not too high $(\gamma>\alpha)$, the own-price effect in the brand-name market is lower than the own-price effect in the generic market and the cross-price effect. Thus, there is no incentive to produce generics. Indeed, to produce generics would decrease the monopoly profit earned on the brand-name product. Moreover, the profit earned on the generic product would not compensate this loss.

\subsubsection{Merger incentive}

In order to determine brand-name firm's merger incentive, we compare its merger payoff and its status quo payoff. Let $\Sigma_{1}(\alpha, \beta, \gamma)$ be the merger gain and $\sigma_{1}(\alpha, \beta, \gamma)$ the opportunity cost lost by the firm when it merges, i.e the status quo payoff.

The merger gain is the difference between the monopoly profit and the buying price. According to the range of demand parameters, there are two monopoly profit functions (see section 2.3.1). The takeover takes place if and only if the brand-name firm's bid is superior or equal to the reservation price. The generic firm always sets the same reservation price, equal to its duopoly profit. ${ }^{12}$ Indeed, we assume that it can not ask more because, refusing to sell, it realizes this duopoly profit. In order to simplifly

\footnotetext{
${ }^{12}$ The unique strategy of the generic firm is to give an asking price equal to $\Pi_{g}^{D^{*}}$.
} 
the analysis, we assume that a bid equal to the reservation price makes the generic firm indifferent between whether to proceed with the sale or not. In this case, it chooses to be sold. Thus, in order to merge, the brand-name firm makes a bid equal to the reservation price, i.e generic firm's duopoly profit. In the merger case, the purchase price is then equal to the duopoly profit. The merger gain is:

$$
\Sigma_{1}(\alpha, \beta, \gamma)=\left\{\begin{array}{c}
\Pi_{b}^{M M^{*}}-\Pi_{g}^{D^{*}} \text { in the case where } \frac{\gamma}{2}<\alpha<\gamma \\
\Pi_{b}^{M^{*}}-\Pi_{g}^{D^{*}} \text { in the case where } \alpha>\gamma
\end{array}\right.
$$

Concerning the opportunity cost, it is equal to profit given up by the brand-name firm when the latter decides to merge, i.e its duopoly profit (status quo):

$$
\sigma_{1}(\alpha, \beta, \gamma)=\Pi_{b}^{D *}
$$

Therefore, there is an incentive to merge if and only if:

$$
F(\alpha, \beta, \gamma)=\Sigma_{1}(\alpha, \beta, \gamma)-\sigma_{1}(\alpha, \beta, \gamma) \geq 0
$$

We show that $F(\alpha, \beta, \gamma) 0$ for $\alpha \in\left[\frac{\gamma}{2}, \beta[\right.$.

Proof. see appendix D.

Remark 3 In the duopoly case, the merger always takes place. We claim that the equilibrium of this game is the merger situation. 
The monoplization leads to an increase in market power and then to an increase in profits. This compensates for generic firm's buying price. Indeed, if the goods were homogeneous, the market power gain would be higher than the loss related to the buying price (Kamien and Zang, 1990). In our study, goods are not perfect substitutes. Thus, there is a drop in the merger gain since the generic market is more sensitive to price. But, on the other hand, generic firm's buying price also decreases since generic firm's profit is lower than if this firm produces the homogeneous product. This shows that results of Kamien and Zang (1990) are robust if one takes away the perfectly substitutable goods assumption. Now, we show that pseudo-generics production possibility may modify incentives to merge.

\section{Pseudo-generic and "delayed" merger}

In this section, we consider that the brand-name laboratory can produce a pseudogeneric good. We study incentives to merge within this framework. If a takeover takes place after pseudo-generics production, it is called "delayed" merger. The brand-name firm maximizes the sum of its profit earned on brand-name goods and its profit earned on pseudo-generic goods. In this case, we recall that $Q_{G}=q_{g}+q_{p g}$ where $q_{g}$ is the generic output and $q_{p g}$ the pseudo-generic output and that, for consumers, generic and pseudo-generic goods are homogeneous (Hollis, 2002). In the rest of the paper, we call "pseudo-duopoly" the industry structure in which the brand-name firm produces pseudo-generics.

For the benchmark case, we showed that the brand-name firm monopolizes the industry. Another strategy is now possible: the brand-name firm can produce pseudo- 
generic goods. Consequently, we consider a second step: having produced pseudogenerics during the first production period, the brand-name firm can either continue to produce pseudo-generics, or merge with the generic firm. Therefore, we consider a twostage game:

In the first stage, there are three states of the world: the two previous states (i.e the merger and the status quo) and a new one in which the brand-name firm decides to produce pseudo-generics. After this stage, a production period takes place. In the second stage, if the brand-name produced pseudo-generics, two states of the world are available: merger or pseudo-duopoly ${ }^{13}$. Otherwise, the industry structure does not change. After this stage, competition takes place on an infinite horizon.

We solve backward the non-cooperative game in order to compute sub-game perfect Nash equilibria (SPNE). In the second stage of the game, we determine the subgame equilibrium: we find the equilibrum between to merge or not, pseudo-generics production being decided at the first stage (section 3.2). Finally, we find the SPNE of the game (section 3.3). In order to solve the game, we previously determine the pseudoduopoly profit functions (section 3.1).

\footnotetext{
${ }^{13}$ After pseudo-generics production, the merger can only take place at the second stage of the game (see section 3.3 for more details).
} 


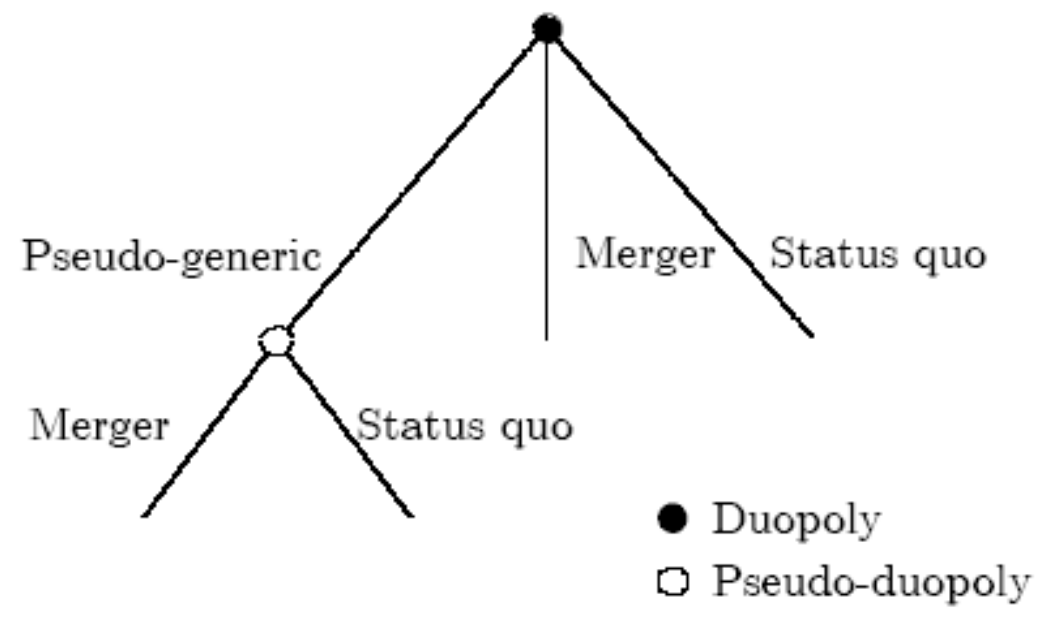

Figure 2

\subsection{Pseudo-generics production}

We have to study the market structure in which the brand-name firm produces pseudo-generics: the pseudo-duopoly structure. Indeed, the two firms compete à la Cournot but the brand-name firm produces two drugs: brand-name and pseudo-generic goods. Obviously, the generic firm produces the generic good. Furthermore, the generic is present in the market before the pseudo-generic firm's entry, thus benefiting from the first mover advantage (Grabowsky and Vernon, 1992). This advantage confers on it the generic market leadership. So, we talk about Cournot-Stackelberg competition in this pseudo-duopolistic industry ${ }^{14}$. Let $\Pi_{g}^{P}$ be generic laboratory's profit and $\Pi_{b}^{P}$ be brandname laboratory's profit.

To compute the equilibrium profits, it is necessary to determine the reaction function $R F\left(q_{b}, q_{g}\right)$ concerning pseudo-generics (see appendix E). Substituting

\footnotetext{
${ }^{14}$ Our results are robusts to the competition $\grave{a}$ la Cournot-Nash, and moreover, if the leader of the generic market is the brand-name firm. Indeed, these assumptions do not provide any qualitatively different results.
} 
$R F\left(q_{b}, q_{g}\right)$ in both profit functions, we derive the equilibrium outputs from the first order conditions:

$$
\begin{gathered}
q_{g}^{P *}=\frac{1}{2 \beta} . \\
q_{b}^{P *}=\frac{1}{2} \frac{\beta-\gamma}{\alpha \beta-\gamma^{2}} .
\end{gathered}
$$

Substituting (16) and (17) in $R F\left(q_{b}, q_{g}\right)$, we derive the pseudo-generics equilibrium output:

$$
q_{p g}^{P *}=\frac{1}{4} \frac{\alpha \beta-2 \gamma \beta+\gamma^{2}}{\beta\left(\alpha \beta-\gamma^{2}\right)} .
$$

We deduce the equilibrium profits:

$$
\begin{gathered}
\Pi_{g}^{P *}=\frac{1}{8 \beta} . \\
\Pi_{b}^{P *}=\frac{1}{16} \frac{\alpha \beta+4 \beta^{2}-8 \gamma \beta+3 \gamma^{2}}{\beta\left(\alpha \beta-\gamma^{2}\right)} .
\end{gathered}
$$

The pseudo-duopoly exists if the pseudo-generics equilibrium output is positive. This is the case if:

$$
\alpha>A(\beta, \gamma) \text {, with } A(\beta, \gamma)=\frac{\gamma(2 \beta-\gamma)}{\beta}
$$


To solve for SPNE of the game, we compute the sub-game equilibrium of the second stage. In particular, we determine the merger incentive in the pseudo-duopolistic structure.

\subsection{Second stage: merger incentive in the pseudo-duopoly market}

We study incentives to merge in the case where the industry is initially pseudoduopolistic. These incentives change compared to the duopoly case. In this framework, the brand-name producer chooses between two events. It can merge or stay in the same market structure. In the first case, it monopolizes the market and produces brand-name goods and generics because the product differentiation is high enough $(\alpha>\gamma$ : see remark 2). Indeed, the pseudo-duopoly structure can exist only if $\alpha>A(\beta, \gamma)$. Moreover, $A(\beta, \gamma)>\gamma$. The generic firm chooses between two strategies: to accept the buying price or to reject it. This firm always sets a reservation price equal to its profit in the status quo case, i.e its pseudo-duopoly profit $\left(\Pi_{g}^{P *}\right)$. In order to merge, we assume that the brand-name firm has only to make a bid equal to the reservation price of the generic firm.

The brand-name firm has an incentive to acquire the generic producer if its merger gain is higher than its opportunity cost. Let $\Sigma_{2}(\alpha, \beta, \gamma)$ be the merger gain:

$$
\Sigma_{2}(\alpha, \beta, \gamma, \delta)=\Pi_{b}^{M *}-\Pi_{g}^{P *}
$$


Let $\sigma_{2}(\alpha, \beta, \gamma, \delta)$ be the opportunity cost. In other words, it is about brand-name firm's profit when this firm does not merge (status quo):

$$
\sigma_{2}(\alpha, \beta, \gamma, \delta)=\Pi_{b}^{P *}
$$

Thus, the merger incentive exists if and only if:

$$
\Sigma_{2}(\alpha, \beta, \gamma, \delta)-\sigma_{2}(\alpha, \beta, \gamma, \delta)=\frac{\Pi_{b}^{M *}-\Pi_{g}^{P *}-\Pi_{b}^{P *}}{1-\delta} \geq 0
$$

The condition (24) is always verified ${ }^{15}$, thus:

Remark 4 In the pseudo-duopoly regime, the merger always takes place.

We claim that the Nash equilibrium of this sub-game is the merger situation. The merger is possible whatever the demand parameters are. The buying price of the generic firm is lower in the pseudo-duopoly regime than in the duopoly regime because the generic firm is directly competed against. Indeed, generic and pseudo-generic goods are perfect substitutes. Given the sub-game equilibrium found in this section, we turn to the first stage of the game to compute the SPNE.

\subsection{First stage: the "Delayed" merger incentive}

\footnotetext{
${ }^{15}$ Indeed, $\Pi_{b}^{M *}-\Pi_{g}^{P *}-\Pi_{b}^{P *}=\frac{1}{16 \beta}>0$.
} 
Relative to section 2, a new path is analyzed. In section 3.2, we solved the subgame of the second stage. Whatever demand parameters are selected, there is an unique Nash equilibrium: the monopolization of the pseudo-duopoly industry. Therefore, the new path to study is the "delayed" merger (i.e to merge after having produced pseudogenerics). For the brand-name laboratory, the sole interest in this path is to reduce the purchase price of the generic firm. Nevertheless, the brand-name firm gives up the monopoly profit during a production period. Indeed, it would earn the monopoly profit at once by merging before the first production period. ${ }^{16}$

We determined the equilibrium of the second stage in the case where the pseudogeneric drug has been produced at the first stage. Without pseudo-generics, the merger event dominates the status quo event. Thus, there is always monopolization (see section 2.3). In order to find the SPNE of the two-stage game, we must compare two branches of the game tree: either the merger at the beginning of the game, or the "delayed" merger.

The repurchase mechanism is the same as previously. Here, the takeover takes place at the beginning of the second period. We study this new path. The brand-name firm makes a bid for the generic firm. The latter gives a reservation price below which it rejects the offer. If the bid is superior or equal to the reservation price, the takeover takes place. As there is a two-stage game and as the horizon is infinite, payoffs must take into account the rate of discount $\delta .{ }^{17}$

In this section, we determine the "delayed" merger gain. This is the payoff earned by the brand name firm, following this merger path. This path can be analyzed in two

\footnotetext{
${ }^{16}$ Without merger, we exclude pseudo-generics production for more than one period. Indeed, the generic firm's buying price is constant once the pseudo-generic good is produced. Moreover, by merging later, the brand-name firm gives up the monopoly profit for a longer time.
} 
steps because there is a change between the first production period and the following ones. During the first period, the brand-name firm earns a pseudo-duopoly profit. After, it gets a monopoly profit ${ }^{18}$ for an infinite horizon. In order to merge, the brand-name firm has to pay the generic firm's pseudo-duopoly profit for the following periods. Let $\Sigma_{3}(\alpha, \beta, \gamma, \delta)$ be the "delayed" merger gain:

$$
\Sigma_{3}(\alpha, \beta, \gamma, \delta)=\Pi_{b}^{P *}+\frac{\delta \Pi_{b}^{M *}}{1-\delta}-\frac{\delta \Pi_{g}^{P *}}{1-\delta}
$$

In the rest of the paper, the first stage merger is called "standard" merger. In section 2.3, we showed that the "standard" merger is preferred to the status quo. Thus, we have to compare the "delayed" merger gain and the "standard" merger gain. Note that, in the previous section, we computed the "standard" merger gain in a static framework and for a high enough level of product differentiation $\left(\alpha>\frac{\gamma}{2}\right.$, see equality (13)). Now, we restrict the range of parameters because pseudo-generics production may exist only if $\alpha>A(\beta, \gamma)$. Moreover, as the horizon is infinite, the "standard" merger gain is the discounted infinite flow of monopoly profit minus the buying price (i.e the infinite flow of generic firm's duopoly profit). Therefore, we compare the "delayed" merger gain and the discounted infinite flow of "standard" merger gain $\left(\frac{\Sigma_{1}(\alpha, \beta, \gamma)}{1-\delta}\right)$, with $\alpha>A(\beta, \gamma)$. Let $S(\alpha, \beta, \gamma, \delta)$ be the difference between these two gains:

$$
S(\alpha, \beta, \gamma, \delta)=\Sigma_{3}(\alpha, \beta, \gamma, \delta)-\frac{\Sigma_{1}(\alpha, \beta, \gamma)}{1-\delta}=\Pi_{b}^{P *}-\Pi_{b}^{M *}+\frac{\Pi_{g}^{D *}}{1-\delta}-\frac{\delta \Pi_{g}^{P *}}{1-\delta}
$$

\footnotetext{
${ }^{17} \delta=\frac{1}{1+r}$, with $r$ the interest rate.

${ }^{18}$ The pseudo-generic good may be produced only if $\alpha>A(\beta, \gamma)$. Thus, $A(\beta, \gamma)>\gamma$. We deduce that $\alpha>\gamma$ in this framework. Therefore, the monopoly produces two substituable goods.
} 
If $S(\alpha, \beta, \gamma, \delta)>0$, then the "delayed" merger is SPNE of the game. Let us detail $S(\alpha, \beta, \gamma, \delta)$. Note $c(\beta)=\Pi_{b}^{M *}-\Pi_{b}^{P *}=\frac{3}{16 \beta}$. This is the cost due to the "delayed" merger compared to the "standard" merger. This cost is borne during the first period. Note $g(\alpha, \beta, \gamma, \delta)=\frac{\Pi_{g}^{D *}}{1-\delta}-\frac{\delta \Pi_{g}^{p^{*}}}{1-\delta}$. This is the decrease in the purchase price associated with the "delayed" merger event. Indeed, instead of paying the discounted infinite flow of the generic firm's duopoly profit from the beginning, the brand-name firm pays, at the second stage, the discounted infinite flow of the generic firm's pseudo-duopoly profit.

Proposition 1 The "delayed" merger is the SPNE of this game if and only if:

(i) the own-price effect for the brand-name product is relatively high,

(ii) the own-price effect for the generic product is rather strong compared to the cross-price effect,

(iii) the rate of discount is sufficiently high (i.e $\delta>\overline{\bar{\delta}}(\alpha, \beta, \gamma)$ ).

Proof. We show that $S(\alpha, \beta, \gamma, \delta)>0$ for :

$-\alpha>\alpha_{2}(\beta, \gamma)$,

$-\beta>\gamma\left(\frac{1}{2}+\frac{\sqrt{2}}{2}\right)$,

$-\delta \in] \overline{\bar{\delta}}(\alpha, \beta, \gamma), 1\left[\right.$, with $\overline{\bar{\delta}}(\alpha, \beta, \gamma)=\frac{\left(-16 \beta^{2}\right) \alpha^{2}+\left(64 \beta^{2} \gamma-24 \beta \gamma^{2}\right) \alpha+\left(3 \gamma^{4}-16 \beta^{2} \gamma^{2}\right)}{\left(4 \alpha \beta-\gamma^{2}\right)^{2}}$

For more details, see appendix $\mathrm{F}$ for the study of $c(\beta)$ and the study of $g(\alpha, \beta, \gamma, \delta)$. See also appendix $\mathrm{G}$ for the study of $S(\alpha, \beta, \gamma, \delta)$.

Intuitively, if the own-price effect for the brand-name product is relatively high, then the "delayed" merger gain increases compared to the "standard" merger gain. 
Indeed, the generic's firm duopoly profit increases with the brand-name market pricesensitivity $(\alpha)$ while the generic's firm pseudo-duopoly profit is independent of this sensitivity. Furthermore, if the generic market price-sensitivity $(\beta)$ is high enough, the first period loss due to the "delayed" merger is relatively low. Under these parameter conditions, there is a rate of discount high enough such as the earnings of the second period (the "delayed" merger purchase price is lower than the "standard" merger one: $\left.\Pi_{g}^{P *}<\Pi_{g}^{D *}\right)$ exceeds the loss of the first period.

Now, we study how the profitability zone of "delayed" mergers $(\delta \in] \overline{\bar{\delta}}(\alpha, \beta, \gamma), 1\left[\right.$ ) is affected by demand shocks. We show that $\frac{\partial \overline{\bar{\delta}}(\alpha, \beta, \gamma)}{\partial \alpha}<0$, $\frac{\partial \overline{\bar{\delta}}(\alpha, \beta, \gamma)}{\partial \beta}>0$, and $\frac{\partial \overline{\bar{\delta}}(\alpha, \beta, \gamma)}{\partial \gamma}>0$. The proof is given in appendix $\mathrm{H}$.

Remark 5 The "delayed" merger profitability increases (respectively decreases) when the brand-name market price-sensitivity $(\alpha)$ increases, given the generic market price-sensitivity $(\beta)$ and the cross price-sensitivity $(\gamma)$ (respectively when $\beta$ increases given $\alpha$ and $\gamma$ or when $\gamma$ increases given $\alpha$ and $\beta$ ).

Intuitively, the minimum rate of discount permitted to achieve a "delayed" merger decreases according to the price-sensitivity increase in the brand-name market, given other demand parameters. In other words, this relative increase in the price-sensitivity in the brand-name market allows the gain in purchase price due to the "delayed" merger to increase. So, the development of this merger gain does not need to be very high to compensate for the loss undergone during the first period since the brand-name firm 
does not merge at the first stage. This means that the "delayed" merger is profitable for low rates of discount when the price-sensitivity in the brand-name market is high.

We show that $\overline{\bar{\delta}}(\overline{\bar{\alpha}}(\beta, \gamma), \beta, \gamma)=0$. The proof is given in appendix I.

Remark 6 There exists a threshold $\overline{\bar{\alpha}}(\beta, \gamma)$ (a very high product differentiation) such as if $\alpha>\overline{\bar{\alpha}}(\beta, \gamma)$, then $\overline{\bar{\delta}}(\alpha, \beta, \gamma) \leq 0$. In this extreme case, the "delayed" merger takes place whatever the rate of discount is.

\section{4 "Delayed" merger and "Predatory" merger}

In this section, we focus on merger strategy effects on pseudo-generics production. Therefore, we analyze the pseudo-generics production decision when mergers are not considered (section 4.1). Afterwards, relating to mergers, we show there is an incentive to produce pseudo-generics that did not previously exist. This merger is called "predatory" merger. Indeed, the merger strategy may trigger pseudo-generics' production. Contrary to the predation literature, in our paper, the predation is provoked by pseudo-generics production and not by predatory pricing. We conclude this section by policy recommandations (section 4.2).

\subsection{Comparison of the duopoly and the pseudo-duopoly regimes:}

Excluding mergers, we determine under which conditions the brand-name firm produces pseudo-generics, and the market, as a consequence, becomes pseudo- 
duopolistic. To find these conditions, we compare brand-name firm's duopoly and pseudo-duopoly profits:

Proposition 2 For a high product differentiation $(\alpha>\bar{\alpha}(\beta, \gamma))$, the brand-name laboratory produces pseudo-generics.

Proof. See appendix J. Moreover,by hypothesis $\alpha<\beta$, thus

$$
\begin{gathered}
\text { If } \bar{\alpha}(\beta, \gamma)>\beta \text { then } \Pi_{b}^{D *}>\Pi_{b}^{P *} \text { for } \alpha \in\left[\frac{\gamma}{2}, \beta[,\right. \\
\text { If } \bar{\alpha}(\beta, \gamma)<\beta \text { then }\left\{\begin{array}{l}
\Pi_{b}^{D *}>\Pi_{b}^{P *} \text { for } \alpha \in\left[\frac{\gamma}{2}, \bar{\alpha}(\beta, \gamma)\right] . \\
\Pi_{b}^{P *}>\Pi_{b}^{D *} \text { for } \alpha \in[\bar{\alpha}(\beta, \gamma), \beta[.
\end{array}\right.
\end{gathered}
$$

Remark 7 When $\alpha \in\left[\frac{\gamma}{2}, A(\beta, \gamma)[\right.$, the pseudo-duopoly can not exist and thus the duopoly takes place. Finally, for low product differentiation $(\gamma>2 \alpha)$, the generic producer is excluded from the industry and the brand-name firm monopolizes the market.

The own-price effect for the brand-name product is lower than the own-price effect for the generic product, but very low relative to the cross-price effect. The firm has an incentive to produce pseudo-generic goods because the increase in profits earned on pseudo-generic products compensates for the decrease in profits earned on brandname drugs. This is because of the weakness of the cross-price effect.

Summary of the market structure without merger strategy: 
If $\beta<\bar{\alpha}(\beta, \gamma)$ :

\begin{tabular}{|c|c|c|}
\hline$\alpha$ values & 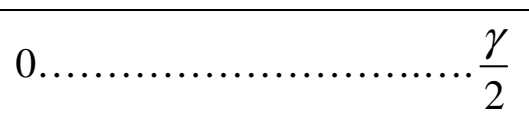 & 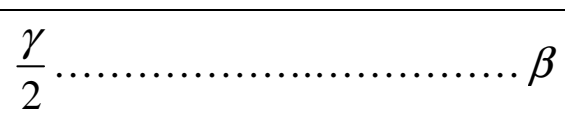 \\
\hline Market structure & Monoproduct monopoly & Duopoly \\
\hline
\end{tabular}

Table 1

If $\beta>\bar{\alpha}(\beta, \gamma)$ :

\begin{tabular}{|l|l|l|l|}
\hline$\alpha$ values & $0 \ldots \ldots \ldots \ldots \ldots . . \frac{\gamma}{2}$ & $\frac{\gamma}{2} \ldots \ldots \ldots \ldots \ldots . \bar{\alpha}(\beta, \gamma)$ & $\bar{\alpha}(\beta, \gamma) \ldots \ldots \ldots \ldots \ldots \ldots \beta$ \\
\hline $\begin{array}{l}\text { Market } \\
\text { structure }\end{array}$ & $\begin{array}{l}\text { Monoproduct } \\
\text { monopoly }\end{array}$ & Duopoly & Pseudo-duopoly \\
\hline
\end{tabular}

Table 2

Remark 8 Note ${ }^{19}$ that $\overline{\bar{\alpha}}(\beta, \gamma)>\bar{\alpha}(\beta, \gamma)$.

\section{2 "Predatory" merger and competition policy}

When a "delayed" merger takes place, the brand-name firm has to produce pseudo-generics during the first period. This firm gives up the monopoly profit it would have earned, by merging at the first stage of the game. Nevertheless, it buys the generic

${ }^{19} F(\alpha=\overline{\bar{\alpha}}(\beta, \gamma), \beta, \gamma)=-2 \gamma^{3}(\gamma-2 \beta)^{2}(4 \beta+3 \gamma+2 \sqrt{3} \beta+\sqrt{3} \gamma)<0$. From appendix I, $\frac{\Pi_{b}^{D *}}{\Pi_{b}^{p *}}<1$, then $\overline{\bar{\alpha}}(\beta, \gamma)>\bar{\alpha}(\beta, \gamma)$. 
laboratory at a lower cost. We call "predatory" merger a "delayed" merger for which pseudo-generics production has been decided exclusively for a merger motive. This means that the "predatory" merger takes place for a range of demand parameters which excludes the pseudo-generics production when mergers are not considered (see section 4.1). We deduce from this:

Proposition 3 For $\alpha \in\left[\alpha_{2}(\beta, \gamma), \bar{\alpha}(\beta, \gamma)\right]$, if pseudo-generics are produced, it is with the sole purpose of inciting a "predatory" merger.

Proof. We show that $\alpha_{2}(\beta, \gamma)<\bar{\alpha}(\beta, \gamma)$ for $\beta>\gamma\left(\frac{1}{2}+\frac{\sqrt{2}}{2}\right)$ (see appendix K).

We saw, in a framework in which mergers strategies are not considered (section 4.1), that the brand-name firm has no incentive to produce pseudo-generic goods when the price-sensitivity for the brand-name product is weak $(\alpha<\bar{\alpha}(\beta, \gamma))$. However, the "delayed" merger possibility modifies this incentive because the brand-name firm produces pseudo-generic goods even if its profits fall. Indeed, the duopoly profit is larger than the pseudo-duopoly profit. Nevertheless, this production allows the brandname firm to buy the generic firm at a lower price. In the same manner as the predatory pricing studies, the predatory strategy induces a temporary drop in profits. Thus, there is a credibility problem of the predatory strategy. But, as suggested by Saloner (1987), notably by assuming sunk costs, the credibility problem disappears. In our model, such an assumption would not modify qualitatively the results. 
This "predatory" merger is preferred to the "standard" merger under the proposition 1 conditions. Obviously, it is also preferred to the status quo (because the "standard" merger dominates the status quo). Thus, the brand-name firm, when $\alpha_{2}(\beta, \gamma)<\alpha<\bar{\alpha}(\beta, \gamma)$, is ready to sacrifice its duopoly profit for its pseudo-duopoly profit, with the aim of acquiring the generic firm at a lower cost.

From a policy perspective, the absence of consumer surplus analysis in our paper does not allow us to propose recommendations. However, we can anticipate some implications. Obviously, in the absence of efficiency gains, as it is the case in our model, mergers should be blocked. Our model indicates that the pseudo-generics production must be considered by competition authorities as a potential merger signal. More exactly, if demand parameters are such that firms have incentives to produce pseudo-generics when they do not consider mergers $(\alpha>\bar{\alpha}(\beta, \gamma))$, the pseudo-generics production is not a merger signal. We can even consider that if $\bar{\alpha}(\beta, \gamma)<\alpha<\overline{\bar{\alpha}}(\beta, \gamma)$ and that $\delta<\overline{\bar{\delta}}(\alpha, \beta, \gamma)$, the "delayed" merger strategies do not exist. On the other hand, if the demand parameters are such that a "predatory" merger is practicable $\left(\alpha_{2}(\beta, \gamma)<\alpha<\bar{\alpha}(\beta, \gamma)\right)$, the pseudo-generics production surely signals a merger. Indeed, no other strategy could justify such a production because pseudo-duopoly profits are less important than duopoly profits.

\section{Conclusion}

Our paper analyzes mergers in pharmaceutical markets. More exactly, we prove that the pseudo-generics' production may be a means towards a lower cost merger. 
Indeed, this strategy reduces the purchase price of the generic company. We modelize an industry in which a brand-name firm and a generic firm compete à la Cournot. Brand-name and generic goods are considered as imperfect substitutes. This model presents a two-stage non-cooperative game. At each stage, the brand-name firm can purchase its generic competitor. But, at the first stage, the brand-name firm can decide to produce pseudo-generics instead. In this framework, the generic laboratory is a Stackelberg leader on the generic market where two homogeneous goods are available: generic and pseudo-generic products.

Three results emerge. First, without pseudo-generics, the brand-name producer always monopolizes the market. Second, pseudo-generics production may delay the takeover. Indeed, under some conditions, the "delayed" merger dominates the first period merger. Third, the brand-name company can produce pseudo-generics solely to monopolize the industry, even if it is not profitable at first. This strategy can be seen as a predation strategy. Indeed, under some market conditions, the pseudo-generics production reduces the brand-name firm's profit, but this firm nevertheless decides to produce pseudo-generics in order to reduce the purchase price of the generic manufacturer. Two conditions must be satisfied to ensure the profitability of this strategy: the loss due to the pseudo-generics production over a period, must not be too significant. This is the case if the products are differentiated enough i.e if the pseudoduopoly is not too unfavourable. Moreover, the discounted value of the gain relative to the reduction in the purchase price must be high enough. But, the higher product differentiation is, the lower the rate of discount can be.

From a policy perspective, the absence of studies on consumer surplus in our paper does not allow us to propose recommendations. However, we can anticipate some 
implications. Obviously, in the absence of efficiency gains, as it is the case in our model, mergers should be blocked. Nevertheless, we should note that firms always benefit from mergers. Thus, they can spend more for R\&D. This may compensate the consumer surplus decrease due to mergers. First, our model indicates the pseudogenerics production must be considered by competition policy as a potential merger signal. On the other hand, the competition authorities must not neglect the fact that the pseudo-generics entry increases consumer surplus because of the increased competition. Moreover, the consumer surplus analysis is interesting for another reason. Kong and Seldon (2004) show that barriers to entry are created due to the pseudo-generics production. This anti-competitive practice reduces consumer surplus. In our study, generics are present in the industry before pseudo-generics. The latter facilitate mergers and we may think they decrease consumer surplus. Therefore, such a consumer surplus analysis could result in the prohibition of pseudo-generic products and should constitute the main direction for future research.

\section{Appendix A (duopoly):}

Competition à la Cournot between the two firms.

The firms simultaneously maximize their profit functions:

$$
\begin{aligned}
& \Pi_{g}^{D}=p_{g} q_{g}=\left(1-\beta q_{g}-\gamma q_{b}\right) q_{g} . \\
& \Pi_{b}^{D}=p_{b} q_{b}=\left(1-\alpha q_{b}-\gamma q_{g}\right) q_{b} .
\end{aligned}
$$


The first order condition (FOC) of the generic laboratory requires that:

$$
\begin{gathered}
\frac{\partial \Pi_{g}^{D}}{\partial q_{g}}=\left(1-\beta q_{g}-\gamma q_{b}\right)-\beta q_{g}=0 \\
\Rightarrow q_{g}\left(q_{b}\right)=-\frac{1}{2 \beta}\left(\gamma q_{b}-1\right) .
\end{gathered}
$$

The FOC of the brand-name laboratory requires that:

$$
\begin{gathered}
\frac{\partial \Pi_{b}^{D}}{\partial q_{b}}=\left(1-\alpha q_{b}-\gamma q_{g}\right)-\alpha q_{b}=0 \\
\Rightarrow q_{b}\left(q_{g}\right)=-\frac{1}{2 \alpha}\left(\gamma q_{g}-1\right) .
\end{gathered}
$$

The equilibrium outputs are given by solving the following system:

$$
\left\{\begin{array}{l}
q_{g}=-\frac{1}{2 \beta}\left(\gamma q_{b}-1\right) \\
q_{b}=-\frac{1}{2 \alpha}\left(\gamma q_{g}-1\right)
\end{array}\right.
$$

\section{Appendix B (multiproduct monopoly):}

The monopoly chooses simultaneously its two quantities in order to maximize its profit function. 


$$
\begin{gathered}
\Pi_{b}^{M}=p_{b} q_{b}+p_{g} q_{g} \\
\left.=\left(1-\alpha q_{b}-\gamma q_{g}\right) q_{b}+\left(1-\beta q_{g}\right)-\gamma q_{b}\right) q_{g} .
\end{gathered}
$$

The FOC 1 gives us the response function in brand-name output:

$$
\frac{\partial \Pi_{b}^{M}}{\partial q_{b}}=-2 \alpha q_{b}+1-2 \gamma q_{g}=0 \Rightarrow q_{b}\left(q_{g}\right)=-\frac{1}{2 \alpha}\left(2 \gamma q_{g}-1\right)
$$

The FOC 2 gives us the response function in pseudo-generic output:

$$
\frac{\partial \Pi_{b}^{M}}{\partial q_{g}}=-2 \gamma q_{b}-2 \beta q_{g}+1=0 \Rightarrow q_{g}\left(q_{b}\right)=-\frac{1}{2 \beta}\left(2 \gamma q_{b}-1\right)
$$

The equilibrium outputs are given by solving the following system:

$$
\left\{\begin{array}{l}
q_{g}=-\frac{1}{2 \beta}\left(2 \gamma q_{b}-1\right) \\
q_{b}=-\frac{1}{2 \alpha}\left(2 \gamma q_{g}-1\right)
\end{array}\right.
$$

\section{Appendix C (monoproduct monopoly):}

If $\alpha<\gamma$, the monopoly produces only the brand-name product. Therefore, it maximizes the following profit function: 


$$
\Pi_{b}^{M M}=p_{b} q_{b}=\left(1-\alpha q_{b}\right) q_{b}
$$

The FOC give us the equilibrium brand-name output:

$$
\frac{\partial \Pi_{b}^{M M}}{\partial q_{b}}=0 \Rightarrow 1-2 \alpha q_{b}=0 \Rightarrow q_{b}^{M M *}=\frac{1}{2 \alpha} .
$$

\section{Appendix D (merger incentive):}

Case 1: $\alpha \in\left[\frac{\gamma}{2}, \gamma[:\right.$

$$
\begin{gathered}
F(\alpha, \beta, \gamma)=\Pi_{b}^{M M *}-\Pi_{g}^{D^{*}}-\Pi_{b}^{D^{*}} \\
=-\frac{1}{4} \frac{(2 \alpha-\gamma)\left(8 \beta \alpha^{2}-12 \alpha \beta \gamma+2 \alpha \gamma^{2}+\gamma^{3}\right)}{\alpha\left(4 \alpha \beta-\gamma^{2}\right)^{2}} .
\end{gathered}
$$

$\operatorname{sign}(F(\alpha, \beta, \gamma))=-\operatorname{sign}(f(\alpha, \beta, \gamma))$ with:

$$
f(\alpha, \beta, \gamma)=8 \beta \alpha^{2}+\left(-12 \beta \gamma+2 \gamma^{2}\right) \alpha+\gamma^{3}
$$

$f(\alpha, \beta, \gamma)$ is a trinomial in $\alpha$.

$f(\alpha, \beta, \gamma) \leq 0$ for $\alpha \in\left[\frac{\gamma}{2}, \gamma[\right.$. Thus, the merger is profitable in this first case since $F(\alpha, \beta, \gamma) \geq 0$ for $\alpha \in\left[\frac{\gamma}{2}, \gamma[\right.$.

Case 2: $\alpha \in[\gamma, \beta[:$ 


$$
\begin{gathered}
F(\alpha, \beta, \gamma)=\Pi_{b}^{M *}-\Pi_{g}^{D *}-\Pi_{b}^{D^{*}} \\
=\frac{1}{4} \frac{\gamma^{2}\left(4 \alpha \beta^{2}+5 \beta \gamma^{2}-16 \alpha \beta \gamma-2 \gamma^{3}+4 \alpha^{2} \beta+5 \alpha \gamma^{2}\right)}{\left(\alpha \beta-\gamma^{2}\right)\left(4 \alpha \beta-\gamma^{2}\right)^{2}} .
\end{gathered}
$$

$\operatorname{sign}(F(\alpha, \beta, \gamma))=\operatorname{sign}(n(\alpha, \beta, \gamma))$ with:

$$
n(\alpha, \beta, \gamma)=4 \alpha^{2} \beta+\left(4 \beta^{2}-16 \gamma \beta+5 \gamma^{2}\right) \alpha+5 \beta \gamma^{2}-2 \gamma^{3}
$$

$n(\alpha, \beta, \gamma)$ is a trinomial in $\alpha$.

$n(\alpha, \beta, \gamma) \geq 0$ for $\alpha \in[\gamma, \beta[$. Thus, the merger is profitable in this second case since $F(\alpha, \beta, \gamma) \geq 0$ for $\alpha \in[\gamma, \beta[$.

\section{Appendix E (pseudo-duopoly case):}

A Cournot-Stackelberg competition takes place between the two firms. These firms maximize the following profits:

$$
\begin{gathered}
\Pi_{g}^{P}=\left(1-\beta\left(q_{g}+q_{p g}\right)-\gamma q_{b}\right) q_{g} . \\
\Pi_{b}^{P}=\left(1-\alpha q_{b}-\gamma\left(q_{g}+q_{p g}\right)\right) q_{b}+\left(1-\beta\left(q_{g}+q_{p g}\right)-\gamma q_{b}\right) q_{p g} .
\end{gathered}
$$


The generic firm is a Stackelberg leader on its market. Then, we determine the $R F\left(q_{b}, q_{g}\right)$, the reaction function in pseudo-generic products:

$$
\begin{aligned}
& \frac{\partial \Pi_{b}^{P}}{\partial q_{p g}}=-2 \gamma q_{b}-\beta q_{p g}+1-\beta\left(q_{g}+q_{p g}\right)=0 \\
& \Rightarrow q_{p g}=R F\left(q_{b}, q_{g}\right)=-\frac{1}{2} \frac{2 \gamma q_{b}-1+\beta q_{g}}{\beta} .
\end{aligned}
$$

Substituting $R F\left(q_{b}, q_{g}\right)$ in the two profit functions, we obtain:

$$
\begin{gathered}
\Pi_{g}^{P}=\frac{1}{2}\left(1-\beta q_{g}\right) q_{g} . \\
\Pi_{b}^{P}=\frac{1}{4} \frac{\left(\gamma^{2}-\alpha \beta\right) q_{b}^{2}+(\beta-\gamma) q_{b}+\beta^{2} q_{g}^{2}-2 \beta q_{g}+1}{\beta} .
\end{gathered}
$$

The brand-name and generic equilibrium outputs are given by solving the FOC system:

$$
\left\{\begin{array} { c } 
{ \frac { \partial \Pi _ { g } ^ { P } } { \partial q _ { g } } = \frac { 1 } { 2 } - \beta q _ { g } = 0 } \\
{ \frac { \partial \Pi _ { b } ^ { P } } { \partial q _ { b } } = \frac { 1 } { 4 \beta } ( 2 q _ { b } \gamma ^ { 2 } - \gamma + \beta - 2 \alpha \beta q _ { b } ) = 0 }
\end{array} \Rightarrow \left\{\begin{array}{c}
q_{g}^{P *}=\frac{1}{2 \beta} \\
q_{b}^{P *}=\frac{1}{2} \frac{\beta-\gamma}{\alpha \beta-\gamma^{2}}
\end{array}\right.\right.
$$

Substituting $q_{g}^{P *}$ and $q_{b}^{P *}$ into $R F\left(q_{b}, q_{g}\right)$, we deduce pseudo-generic equilibrium output: 


$$
q_{p g}^{P *}=\frac{1}{4} \frac{\alpha \beta-2 \gamma \beta+\gamma^{2}}{\beta\left(\alpha \beta-\gamma^{2}\right)} .
$$

\section{Appendix F (cost and gain study):}

1) $c(\beta)$ analysis:

We have that :

$$
c(\beta)=\frac{3}{16 \beta} .
$$

$c(\beta)>0, \forall \beta$

2) $g(\alpha, \beta, \gamma, \delta)$ analysis:

$$
\begin{aligned}
& g(\alpha, \beta, \gamma, \delta)=\frac{1}{8} \frac{\left(4 \alpha \beta-\gamma^{2}\right)^{2} \delta-8 \beta^{2}(2 \alpha-\gamma)^{2}}{\beta\left(4 \alpha \beta-\gamma^{2}\right)^{2}(\delta-1)} . \\
& g(\alpha, \beta, \gamma, \delta)=0 \text { for } \bar{\delta}(\alpha, \beta, \gamma)=\frac{8 \beta^{2}(2 \alpha-\gamma)^{2}}{\left(4 \alpha \beta-\gamma^{2}\right)^{2}} .
\end{aligned}
$$

Note that we study $g(\alpha, \beta, \gamma, \delta)$ only for $\delta \in[0,1[$. 


$$
\frac{\partial g(\alpha, \beta, \gamma, \delta)}{\partial \delta}=\frac{1}{8} \frac{16 \beta^{2} \alpha^{2}+\left(-32 \beta^{2} \gamma+8 \beta \gamma^{2}\right) \alpha-\gamma^{4}+8 \beta^{2} \gamma^{2}}{\left(4 \alpha \beta-\gamma^{2}\right)^{2} \beta(\delta-1)^{2}}
$$

$\operatorname{sign}\left(\frac{\partial g(\alpha, \beta, \gamma, \delta)}{\partial \delta}\right)=\operatorname{sign}\left(16 \beta^{2} \alpha^{2}+\left(-32 \beta^{2} \gamma+8 \beta \gamma^{2}\right) \alpha-\gamma^{4}+8 \beta^{2} \gamma^{2}\right)$

$16 \beta^{2} \alpha^{2}+\left(-32 \beta^{2} \gamma+8 \beta \gamma^{2}\right) \alpha-\gamma^{4}+8 \beta^{2} \gamma^{2}$ is a trinomial in $\alpha$. Its determinant is $128 \beta^{2} \gamma^{2}(2 \beta-\gamma)^{2}>0$

This trinomial admits two roots:

$$
\begin{aligned}
& \alpha_{1}(\beta, \gamma)=\frac{\beta \gamma-\frac{1}{4} \gamma^{2}-\frac{1}{4} \sqrt{8 \beta^{2} \gamma^{2}-8 \beta \gamma^{3}+2 \gamma^{4}}}{\beta}, \\
& \alpha_{2}(\beta, \gamma)=\frac{\beta \gamma-\frac{1}{4} \gamma^{2}+\frac{1}{4} \sqrt{8 \beta^{2} \gamma^{2}-8 \beta \gamma^{3}+2 \gamma^{4}}}{\beta} .
\end{aligned}
$$

Remark:

$$
\begin{gathered}
\alpha_{1}(\beta, \gamma)-A(\beta, \gamma) \\
=\frac{1}{4} \frac{-4 \beta \gamma+3 \gamma^{2}-\sqrt{2} \gamma(2 \beta-\gamma)}{\beta}<0
\end{gathered}
$$

Therefore, the zone with $\left.\alpha \in]-\infty, \alpha_{1}(\beta, \gamma)\right]$ is excluded from the study zone of the "delayed" mergers because the pseudo-generic can not be produced when $\alpha<A(\beta, \gamma)$.

\section{-Conclusion: two cases are possible}

In the case where $\alpha<\alpha_{2}(\beta, \gamma)$, then $g(\alpha, \beta, \gamma, \delta)$ is decreasing in $\delta$, and $g(\alpha, \beta, \gamma, \delta)=0$ for $\delta=\bar{\delta}(\alpha, \beta, \gamma)$. Note that $\bar{\delta}(\alpha, \beta, \gamma)<1$ for $\alpha<\alpha_{2}(\beta, \gamma)$. When $\delta$ 
is near to $1, g(\alpha, \beta, \gamma, \delta)$ tends towards $-\infty$. Therefore, $g(\alpha, \beta, \gamma, \delta) \geq 0$ for $\delta \in[0, \bar{\delta}(\alpha, \beta, \gamma)]$ and $g(\alpha, \beta, \gamma, \delta)<0$ for $\delta \in[\bar{\delta}(\alpha, \beta, \gamma), 1[$

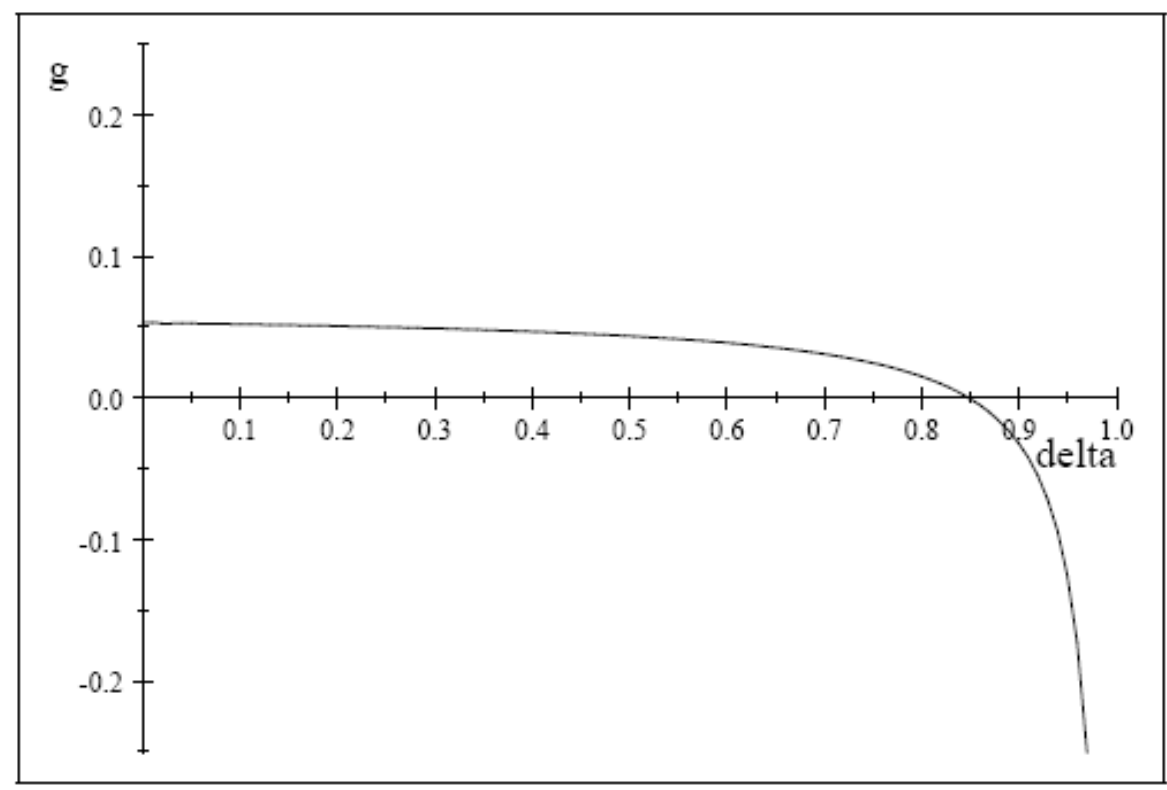

Figure 3: the "delayed" merger gain relative to the "standard" merger gain (for

$$
\left.\alpha<\alpha_{2}(\beta, \gamma)\right)
$$

In the case where $\alpha>\alpha_{2}(\beta, \gamma)$, then $g(\alpha, \beta, \gamma, \delta)$ is increasing in $\delta$, and $g(\alpha, \beta, \gamma, \delta)=0$ for $\delta=\bar{\delta}(\alpha, \beta, \gamma)$. Note that $\bar{\delta}(\alpha, \beta, \gamma)>1$ for $\alpha>\alpha_{2}(\beta, \gamma)$. When $\delta$ is near to $1, g(\alpha, \beta, \gamma, \delta)$ tends towards $+\infty$. Therefore, $g(\alpha, \beta, \gamma, \delta)>0$ for $\delta \in[0,1]$. 


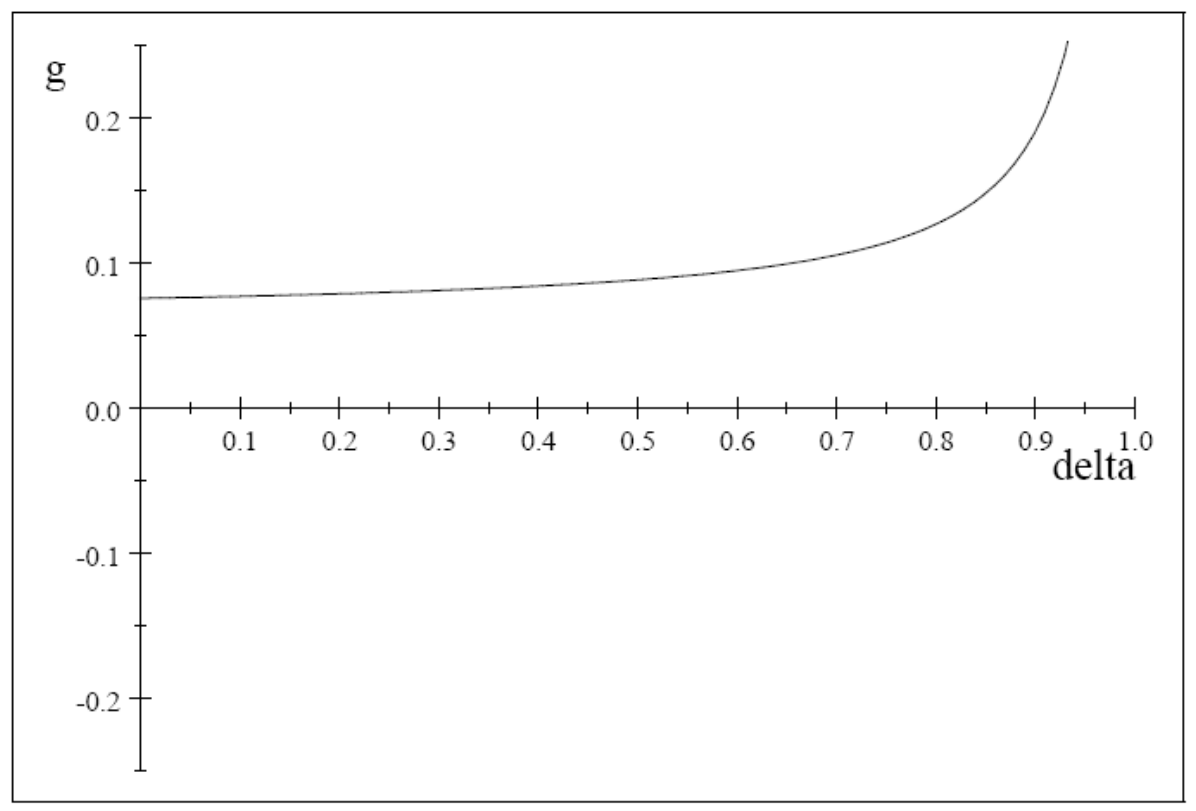

Figure 4: the "delayed" merger gain relative to the "standard" merger gain (for

$$
\left.\alpha>\alpha_{2}(\beta, \gamma)\right)
$$

\section{Appendix G (study of the difference between}

\section{"delayed" merger incentive and "standard" merger incentive):}

The difference between cost and gain associated to "delayed" merger relative to "standard" merger is given by:

$$
\begin{gathered}
S(\alpha, \beta, \gamma, \delta)=g(\alpha, \beta, \gamma, \delta)-c(\beta) \\
=\frac{\left(16 \alpha^{2} \beta^{2}-8 \alpha \beta \gamma^{2}+\gamma^{4}\right) \delta}{16\left(\gamma^{2}-4 \alpha \beta\right)^{2} \beta(1-\delta)}
\end{gathered}
$$




$$
+\frac{\left(16 \alpha^{2} \beta^{2}-64 \alpha \beta^{2} \gamma+24 \alpha \beta \gamma^{2}+16 \beta^{2} \gamma^{2}-3 \gamma^{4}\right)}{16\left(\gamma^{2}-4 \alpha \beta\right)^{2} \beta(1-\delta)} .
$$

As $c(\beta)$ is independent from $\delta, S(\alpha, \beta, \gamma, \delta)$ variation is the same than $g(\alpha, \beta, \gamma, \delta)$ variation. Indeed, $S(\alpha, \beta, \gamma, \delta)$ is a monotonous transformation of the $g(\alpha, \beta, \gamma, \delta)$ function.

$$
S(\alpha, \beta, \gamma, \delta)=0 \text { for: }
$$

$$
\overline{\bar{\delta}}(\alpha, \beta, \gamma)=\frac{\left(-16 \beta^{2}\right) \alpha^{2}+\left(64 \beta^{2} \gamma-24 \beta \gamma^{2}\right) \alpha+\left(3 \gamma^{4}-16 \beta^{2} \gamma^{2}\right)}{\left(4 \alpha \beta-\gamma^{2}\right)^{2}} .
$$

$$
\overline{\bar{\delta}}(\alpha, \beta, \gamma)=1 \text { for } \alpha_{1}(\beta, \gamma) \text { and } \alpha_{2}(\beta, \gamma) \text {. }
$$

Same manner as for $\bar{\delta}(\alpha, \beta, \gamma)$, we deduce that $\overline{\bar{\delta}}(\alpha, \beta, \gamma)>1$ for $\alpha<\alpha_{2}(\beta, \gamma)$ and $\overline{\bar{\delta}}(\alpha, \beta, \gamma)<1$ for $\alpha>\alpha_{2}(\beta, \gamma)$.

- Conclusion: two cases are possible

If $\alpha<\alpha_{2}(\beta, \gamma)$, then $S(\alpha, \beta, \gamma, \delta)$ is decreasing in $\delta$ and tends towards $-\infty$ when $\delta$ tends towards 1 . As $S(\alpha, \beta, \gamma, \delta)$ does not admit a root in this case, we can affirm that $S(\alpha, \beta, \gamma, \delta)<0$. This means that the "standard" merger is always preferred to the "delayed" merger for these parameters values. The "standard" merger being 
always advantageous, then one will have always this merger type at the Nash equilibrium.

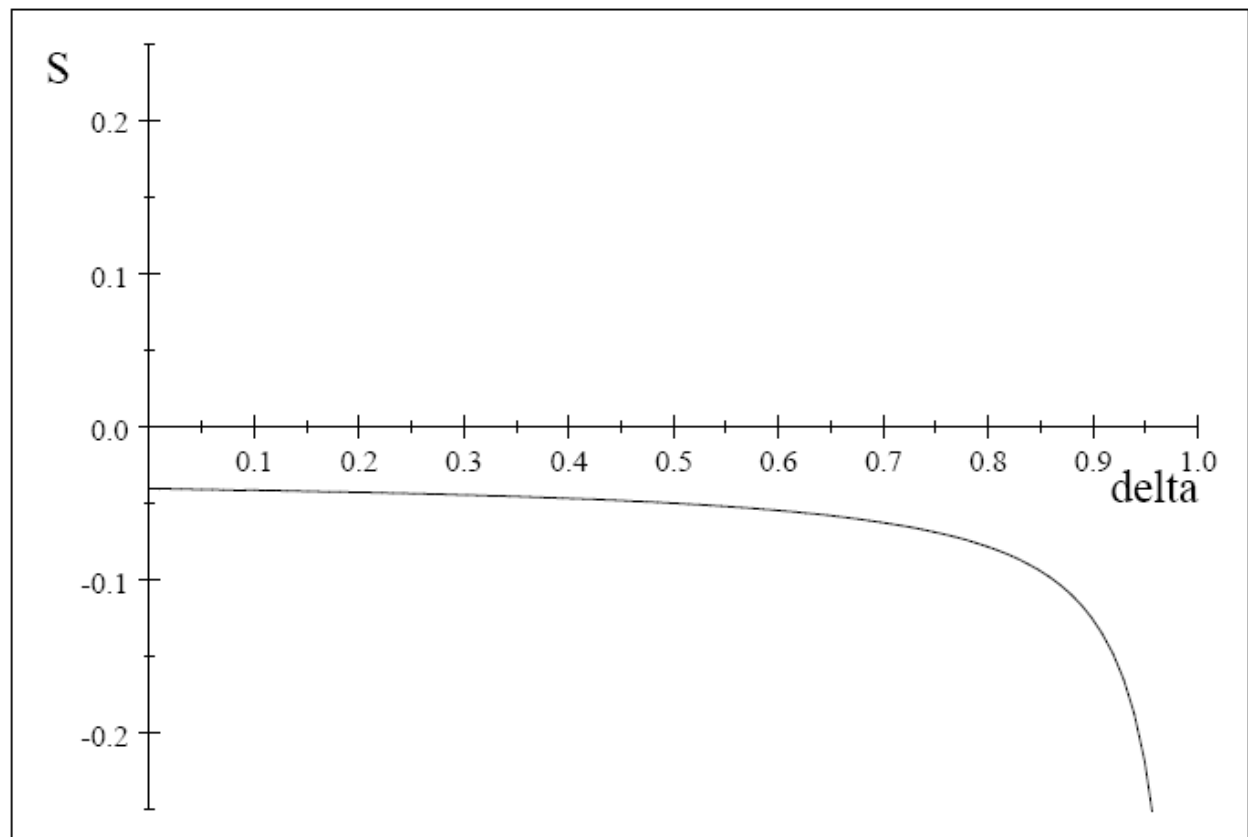

Figure 5: incentive difference between the "strategic" merger gain and the

"delayed" merger gain (for $\alpha<\alpha_{2}(\beta, \gamma)$ )

If $\alpha>\alpha_{2}(\beta, \gamma)$ (possible only for $\beta>\gamma\left(\frac{1}{2}+\frac{\sqrt{2}}{2}\right)$ ), then $S(\alpha, \beta, \gamma, \delta)$ is increasing with $\delta$ and when $\delta$ tends towards $1, S(\alpha, \beta, \gamma, \delta)$ tends towards $+\infty . S(\alpha, \beta, \gamma, \delta)=0$ for $\delta=\overline{\bar{\delta}}(\alpha, \beta, \gamma)$. We deduce that $S(\alpha, \beta, \gamma, \delta) \geq 0$ for $\delta \in[\overline{\bar{\delta}}(\alpha, \beta, \gamma), 1[$. Therefore, the "delayed" merger is the Nash equilibrium of the game. On the contrary, if $\delta \in[0, \overline{\bar{\delta}}(\alpha, \beta, \gamma)[$, the "standard" merger is the Nash equilibrium. 


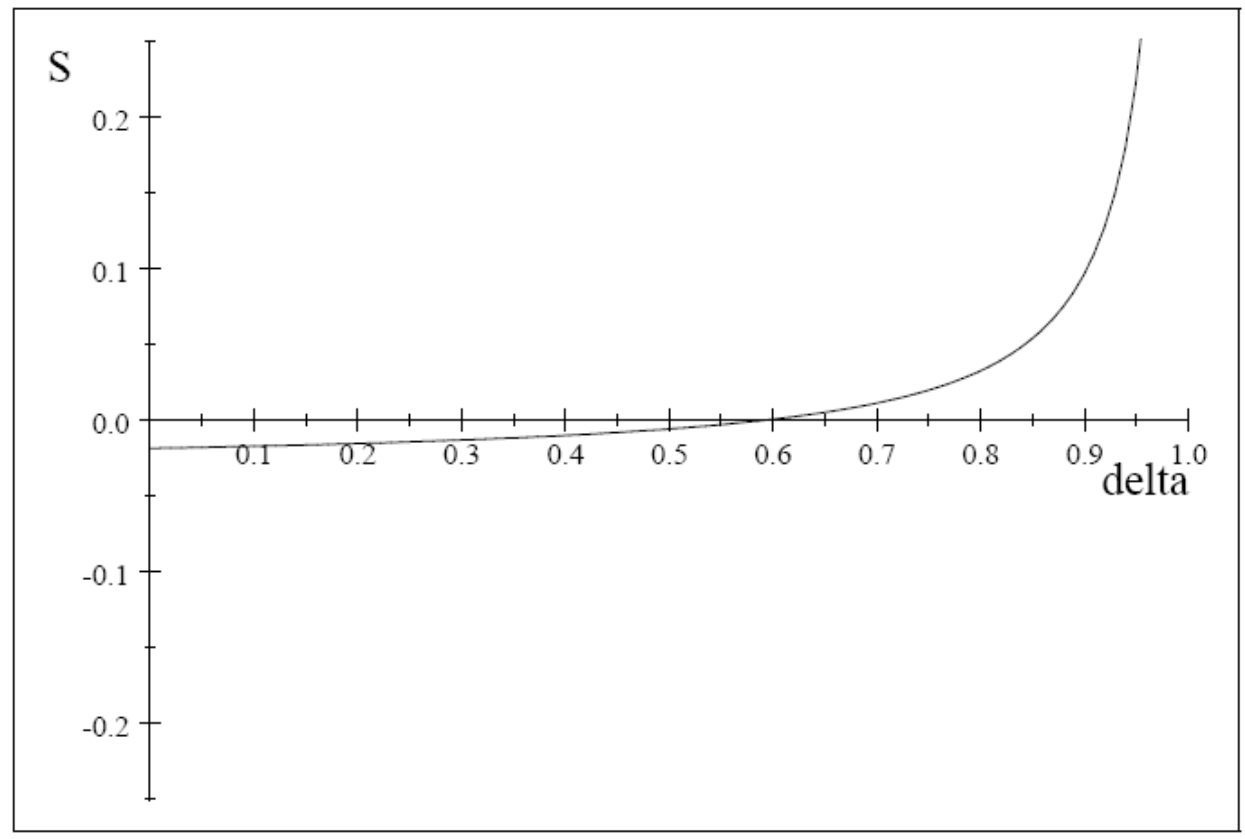

Figure 6: incentive difference between the "delayed" merger gain and the

$$
\text { "standard" merger gain (for } \alpha>\alpha_{2}(\beta, \gamma) \text { ) }
$$

Two Nash equilibria are possible according to the values of demand and actualization parameters.

Remark: Note that, if $\bar{\alpha}(\beta, \gamma)>\alpha>\alpha_{2}(\beta, \gamma)$ (only possible if $\beta>\gamma\left(\frac{1}{2}+\frac{\sqrt{2}}{2}\right)$ ) and if $\delta \in[\overline{\bar{\delta}}(\alpha, \beta, \gamma), 1[$, the brand-name firm produces pseudo-generics in a first time then purchases the generic firm in a second time. At first, the generic firm adapts its generic output because of the pseudo-generics production, then accepts to be sold at a price equal to its pseudo-duopoly profit.

\section{Appendix H (static comparative analysis):}


A discounted rate superior to the treshold $\overline{\bar{\delta}}(\alpha, \beta, \gamma)$ is a necessary condition to the "delayed" merger.

$$
\overline{\bar{\delta}}(\alpha, \beta, \gamma)=\frac{\left(-16 \beta^{2}\right) \alpha^{2}+\left(64 \beta^{2} \gamma-24 \beta \gamma^{2}\right) \alpha+\left(3 \gamma^{4}-16 \beta^{2} \gamma^{2}\right)}{\left(4 \alpha \beta-\gamma^{2}\right)^{2}}
$$

$\frac{\partial \overline{\bar{\delta}}(\alpha, \beta, \gamma)}{\partial \alpha}=\frac{64 \gamma(\gamma-2 \alpha)(\gamma-2 \beta) \beta^{2}}{\left(\gamma^{2}-4 \alpha \beta\right)^{3}}<0$ for $\alpha>\frac{\gamma}{2}$. As $\alpha_{2}(\beta, \gamma)>\frac{\gamma}{2}$ and $\overline{\bar{\delta}}(\alpha, \beta, \gamma)$ is defined for $\alpha>\alpha_{2}(\beta, \gamma)$, then $\frac{\partial \overline{\bar{\delta}}(\alpha, \beta, \gamma)}{\partial \alpha}<0$ for the range of parameters values concerning "delayed" mergers.

$$
\begin{aligned}
& \frac{\partial \overline{\bar{\delta}}(\alpha, \beta, \gamma)}{\partial \beta}=-32 \beta \frac{\gamma^{2}(\gamma-2 \alpha)^{2}}{\left(\gamma^{2}-4 \alpha \beta\right)^{3}}>0 . \\
& \frac{\partial \overline{\bar{\delta}}(\alpha, \beta, \gamma)}{\partial \gamma}=32 \frac{\beta^{2}(\gamma-2 \alpha)}{\left(\gamma^{2}-4 \alpha \beta\right)^{3}}\left(\gamma^{2}-4 \alpha \gamma+4 \alpha \beta\right)>0 \quad \text { for } \quad \alpha>\frac{\gamma}{2} . \quad \text { As } \quad \alpha_{2}(\beta, \gamma)>\frac{\gamma}{2} \quad \text { and }
\end{aligned}
$$

$\overline{\bar{\delta}}(\alpha, \beta, \gamma)$ is defined for $\alpha>\alpha_{2}(\beta, \gamma)$, then $\frac{\partial \overline{\bar{\delta}}(\alpha, \beta, \gamma)}{\partial \gamma}<0$ for the range of parameters values concerning "delayed" mergers.

\section{Appendix I (discounted rate neutrality):}

We showed in appendix $\mathrm{H}$ that $\frac{\partial(\overline{\bar{\delta}}(\alpha, \beta, \gamma))}{\partial \alpha}<0$ for $\alpha>\alpha_{2}(\beta, \gamma)$.

$$
\overline{\bar{\delta}}(\alpha, \beta, \gamma)=0 \quad \text { for } \quad \underline{\underline{\alpha}}(\beta, \gamma)=-\frac{1}{4 \beta}\left(-2 \sqrt{3} \gamma^{2}+3 \gamma^{2}-8 \beta \gamma+4 \sqrt{3} \beta \gamma\right) \quad \text { and }
$$

$$
\begin{gathered}
\overline{\bar{\alpha}}(\beta, \gamma)=-\frac{1}{4 \beta}\left(2 \sqrt{3} \gamma^{2}+3 \gamma^{2}-8 \beta \gamma-4 \sqrt{3} \beta \gamma\right) \\
\underline{\underline{\alpha}}(\beta, \gamma)>0 \text { and } \overline{\bar{\alpha}}(\beta, \gamma)>0
\end{gathered}
$$


Moreover, $\quad \alpha_{2}(\beta, \gamma)-\underline{\underline{\alpha}}(\beta, \gamma)=\frac{1}{4} \gamma \frac{-\beta(2 \sqrt{2}-4 \sqrt{3}+4)+\gamma(\sqrt{2}-2 \sqrt{3}+2)}{\beta}>0 \quad$ and
$\alpha_{2}(\beta, \gamma)-\bar{\alpha}(\beta, \gamma)=-\frac{1}{4} \gamma \frac{\beta(2 \sqrt{2}+4 \sqrt{3}+4)-\gamma(\sqrt{2}+2 \sqrt{3}+2)}{\beta}<0$.
Therefore, in the "delayed" merger zone (i.e $\left.\alpha>\alpha_{2}(\beta, \gamma)\right), \overline{\bar{\delta}}(\alpha, \beta, \gamma)$ is decreasing in $\alpha$ and $\overline{\bar{\delta}}(\alpha, \beta, \gamma)=0$ for $\alpha=\overline{\bar{\alpha}}(\beta, \gamma)$.

\section{Appendix J (comparison of the two structures):}

To simplify the comparison, we analyze the ratio $\frac{\Pi_{b}^{D *}}{\Pi_{b}^{P *}}$ rather than the difference $\Pi_{b}^{D *}-\Pi_{b}^{P *}$

$$
\begin{gathered}
\text { Let } \frac{\Pi_{b}^{D^{*}}}{\Pi_{b}^{P^{*}}}=\frac{16 \alpha \beta(2 \alpha \beta-\gamma)^{2}\left(\alpha \beta-\gamma^{2}\right)}{\left(4 \alpha \beta-\gamma^{2}\right)^{2}\left(\alpha \beta+4 \beta^{2}-8 \gamma \beta+3 \gamma^{2}\right)}, \\
\text { For } \alpha>A(\beta, \gamma)>\frac{\gamma}{2}\left\{\begin{array}{l}
\text { if } \frac{\Pi_{b}^{D^{*}}}{\Pi_{b}^{P^{*}}}>1 \text {, then } \Pi_{b}^{D^{*}}>\Pi_{b}^{P^{*}}, \\
\text { if } \frac{\Pi_{b}^{D^{*}}}{\Pi_{b}^{P *}}<1 \text {, then } \Pi_{b}^{D^{*}}<\Pi_{b}^{P^{*}}
\end{array}\right.
\end{gathered}
$$

Thus, two zones appear:

$$
\begin{aligned}
& \alpha \in\left[\frac{\gamma}{2}, \bar{\alpha}(\beta, \gamma)\left[\text { where } \Pi_{b}^{D^{*}}>\Pi_{b}^{P *},\right.\right. \\
& \alpha \in\left[\bar{\alpha}(\beta, \gamma),+\infty\left[\text { where } \Pi_{b}^{P *}>\Pi_{b}^{D^{*}}\right.\right.
\end{aligned}
$$




\section{Appendix K ("predatory" merger):}

We showed in appendix $\mathrm{J}$ that $R(\alpha, \beta, \gamma)$ is concave for $\alpha>A(\beta, \gamma) . R(\alpha, \beta, \gamma)$ admits a maximum for $\alpha_{\max }(\beta, \gamma)=-\frac{1}{12 \beta} \gamma\left(-16 \beta+6 \gamma+\sqrt{160 \beta^{2}+57 \gamma^{2}-192 \beta \gamma}\right)$ with $A(\beta, \gamma)<\alpha_{\max }(\beta, \gamma)<\bar{\alpha}(\beta, \gamma)$.

If $\alpha_{2}(\beta, \gamma)-\alpha_{\text {max }}(\beta, \gamma)<0$ then $\alpha_{2}(\beta, \gamma)<\alpha_{\text {max }}(\beta, \gamma)$ because $\alpha_{2}(\beta, \gamma)>0$.

Let us show that $\alpha_{2}(\beta, \gamma)-\alpha_{\text {max }}(\beta, \gamma)<0$.

$\alpha_{2}(\beta, \gamma)-\alpha_{\max }(\beta, \gamma)=\frac{1}{12 \beta}\left(\gamma \sqrt{160 \beta^{2}-192 \beta \gamma+57 \gamma^{2}}+3 \gamma^{2}-4 \beta \gamma+3 \sqrt{2} \gamma(\gamma-2 \beta)\right)$ $\frac{\partial\left(\alpha_{2}(\beta, \gamma)-\alpha_{\max }(\beta, \gamma)\right)}{\partial \beta}>0$ for $\alpha>A(\beta, \gamma)$.

The "delayed" mergers imply that $\beta>\gamma\left(\frac{1}{2}+\frac{\sqrt{2}}{2}\right)$ (see proposition 2).

If $\beta>\gamma\left(\frac{3-\sqrt{2}}{4-2 \sqrt{2}}\right)$, then $\alpha_{2}(\beta, \gamma)<A(\beta, \gamma)<\bar{\alpha}(\beta, \gamma)$.

If $\quad \gamma\left(\frac{1}{2}+\frac{\sqrt{2}}{2}\right)<\beta<\gamma\left(\frac{3-\sqrt{2}}{4-2 \sqrt{2}}\right), \quad$ then $\quad \alpha_{2}(\beta, \gamma)-\alpha_{\max }(\beta, \gamma)<0 \quad$ because, for $\beta=\gamma\left(\frac{3-\sqrt{2}}{4-2 \sqrt{2}}\right), \quad \alpha_{2}(\beta, \gamma)-\alpha_{\max }(\beta, \gamma)<0 \quad$ and $\quad$ because $\quad \frac{\partial\left(\alpha_{2}(\beta, \gamma)-\alpha_{\max }(\beta, \gamma)\right)}{\partial \beta}>0 \quad$ for $\alpha>A(\beta, \gamma)$. Therefore $\alpha_{2}(\beta, \gamma)<\bar{\alpha}(\beta, \gamma)$ for $\beta>\gamma\left(\frac{1}{2}+\frac{\sqrt{2}}{2}\right)$. 


\section{References}

Caves, R., Whinston, M., Hurwitz, M., 1991. Patent expiration, entry and competition in the U.S pharmaceutical industry. Brookings Papers: Microeconomics, 148.

Ching, A.T.T., 2000. Dynamic equilibrium in the U.S. prescription drug market after patent expiration. Working paper, Ohio State University, Mimeo.

OECD. Competition and regulation issues in the pharmaceutical industry. DAFFE/CLP (2001) 29.

Grabowski, H., Vernon, J., 1992. Brand loyalty, entry, and price competition in pharmaceuticals after the 1984 drug act. Journal of Law and Economics 35, 331-350.

Ferrandiz, J., 1999. The impact of generic goods in the pharmaceutical industry. Health Economics 8, 599-612.

Frank, R., Salkever, D., 1992. Pricing patent loss and the market for pharmaceutical. Southern Economic Journal 59, 165-179.

Frank, R., Salkever, D., 1997. Generic entry and the pricing of pharmaceuticals. Journal of Economics \& Management Strategy 6, 75-90.

Hollis, A., 2002. The importance of being first: evidence from Canadian generic pharmaceutical. Health Economics 11, 723-734.

Hollis, A., 2003. The anti-competitive effects of brand-controlled 'pseudogenerics' in the Canadian pharmaceutical market. Canadian Public Policy 29, 21-32.

Hollis, A., 2005. How do brands" "own generics" affect pharmaceutical prices? Review of Industrial Organization 27, 329-350. 
Kamien, M., Zang, I., 1990. Monopolization by sequential acquisition. The Journal of Law, Economics \& Organization 9, 205-229.

Kong, Y., Seldon, J., 2004. Pseudo-genenric products and barriers to entry in pharmaceutical markets. Review of Industrial Organization 25, 71-86.

Saloner, G., 1987. Predation, mergers, and incomplete information. Rand Journal of Economics 18, 165-186.

Scott Morton, F., 1999. Entry decisions in the generic pharmaceutical industry. Rand Journal of Economics 30, 421-444.

Scott Morton, F., 2000. Barriers to entry, brand advertising, and generic entry in the US pharmaceutical industry. International Journal of Industrial Organization 18, 1085-1104.

Scott Morton, F., 2002. Horizontal integration between brand and generic firms in the pharmaceutical industry. Journal of Economics \& Management Strategy 11, 135168. 